\title{
Mortality in HIV-infected patients with tuberculosis treated with streptomycin and a two-week intensified regimen: Data from an HIV cohort study using inverse probability of treatment weighting
}

Gerardo Alvarez-Uria, Manoranjan Midde, Praveen K Naik

Background. Despite the dramatic scale-up of antiretroviral therapy in low- and middleincome countries, tuberculosis (TB) is still the main cause of death among HIV infected patients in resource-limited settings. Previous studies in patients with TB meningitis suggest that the use of higher doses of common anti-TB drugs could reduce mortality. Methods. Using clinical data from an HIV cohort study in India, we compared the mortality among HIV-infected patients diagnosed with TB according to the regimen received during the first two weeks of treatment: standard anti-tuberculosis therapy (ATT) ( $N=847)$, intensified ATT ( $N=322)$, and intensified ATT with streptomycin $(N=446)$. The intensified ATT comprised double dose of rifampicin and substitution of ethambutol with levofloxacin. Multivariate analysis was performed using Cox proportional hazard models and inverse probability of treatment weighting (IPTW) based on propensity scores. Patients with TB meningitis were excluded. Results. The use of intensified ATT alone did not improve survival. However, when streptomycin was added, the use intensified ATT was associated with reduced mortality in Cox models (adjusted hazard ratio $0.72,95 \%$ confidence interval 0.57-0.91) and after IPTW (hazard ratio $0.77,95 \%$ confidence interval 0.67-0.96). Other factors associated with improved survival were high serum albumin concentration, high CD4 lymphocyte cell-counts, and high glomerular filtration rates. Factors associated with increased mortality were high urea concentrations, being on antiretroviral therapy at the time of ATT initiation and high BUN/creatinine ratio. In an effect modification analysis, the survival benefits of the intensified ATT with streptomycin disappeared in patients with severe hypoalbuminemia. Conclusion. The results of this study are in accordance with a previous study from our cohort involving patients with TB meningitis and suggest that an intensified 2-week ATT with streptomycin could reduce mortality in HIV infected patients with TB. As this is an observational study, we should be cautious about our conclusions, but given the high mortality of HIV-related TB, our findings deserve further research. 
1 Mortality in HIV-infected patients with tuberculosis treated

2 with streptomycin and a two-week intensified regimen: Data

3 from an HIV cohort study using inverse probability of

4 treatment weighting

5

6 Gerardo Alvarez-Uria, Manoranjan Midde, and Praveen Kumar Naik.

7 Department of Infectious Diseases. Rural Development Trust Hospital, Bathalapalli, AP, India.

9 Corresponding author: Gerardo Alvarez-Uria, Department of Infectious Diseases, Bathalapalli

10 Rural Development Trust Hospital. Kadiri Road. Bathalapalli 515661. Anantapur District.

11 Andhra Pradesh. India. Fax/telephone number: +918559242316. Email: gerardouria@gmail.com. 


\section{Abstract}

14 Background. Despite the dramatic scale-up of antiretroviral therapy in low- and middle-income countries, tuberculosis (TB) is still the main cause of death among HIV infected patients in resource-limited settings. Previous studies in patients with TB meningitis suggest that the use of higher doses of common anti-TB drugs could reduce mortality. Methods. Using clinical data from an HIV cohort study in India, we compared the mortality among HIV-infected patients diagnosed with TB according to the regimen received during the first two weeks of treatment: standard anti-tuberculosis therapy (ATT) $(\mathrm{N}=847)$, intensified ATT $(\mathrm{N}=322)$, and intensified

21 ATT with streptomycin $(\mathrm{N}=446)$. The intensified ATT comprised double dose of rifampicin and 22 substitution of ethambutol with levofloxacin. Multivariate analysis was performed using Cox 23 proportional hazard models and inverse probability of treatment weighting (IPTW) based on 24 propensity scores. Patients with TB meningitis were excluded. Results. The use of intensified

25 ATT alone did not improve survival. However, when streptomycin was added, the use intensified ATT was associated with reduced mortality in Cox models (adjusted hazard ratio $0.72,95 \%$ confidence interval $0.57-0.91$ ) and after IPTW (hazard ratio $0.77,95 \%$ confidence interval $0.67-$ 0.96). Other factors associated with improved survival were high serum albumin concentration, high CD4 lymphocyte cell-counts, and high glomerular filtration rates. Factors associated with

30 increased mortality were high urea concentrations, being on antiretroviral therapy at the time of

31 ATT initiation and high BUN/creatinine ratio. In an effect modification analysis, the survival

32 benefits of the intensified ATT with streptomycin disappeared in patients with severe

33 hypoalbuminemia. Conclusion. The results of this study are in accordance with a previous study

34 from our cohort involving patients with TB meningitis and suggest that an intensified 2-week

35 ATT with streptomycin could reduce mortality in HIV infected patients with TB. As this is an 
36 observational study, we should be cautious about our conclusions, but given the high mortality of

37 HIV-related TB, our findings deserve further research.

\section{Introduction}

40 Tuberculosis (TB) accounts for one third of deaths among HIV infected people, and HIV

41 infection is present in 25\% of TB deaths (World Health Organization, 2015). Globally 1.2

42 million people living with HIV had TB in 2014, and 390,000 people died (World Health

43 Organization, 2015). Despite this tremendous burden of preventable deaths, there has not been

44 any major breakthrough in the chemotherapy of HIV-related TB in the last decades.

45 Recent data from a clinical trial and an observational cohort study suggest that increasing the

46 doses of common anti-TB drugs during the initial phase of anti-TB therapy (ATT) could have

47 survival benefits in patients with TB meningitis (Alvarez-Uria et al., 2013a; Ruslami et al.,

48 2013). In a phase two randomized trial investigating the effect of an intensified ATT (iATT)

49 during the first two weeks of treatment, higher exposure to rifampicin was associated with

50 improved survival (Ruslami et al., 2013; Te Brake et al., 2015). In previous studies from our

51 HIV cohort, an iATT during the first days of TB meningitis treatment also achieved improved

52 survival, but only if streptomycin (STM) was added to the regimen (Alvarez-Uria et al., 2015).

53 This finding was intriguing because STM has poor penetration into cerebrospinal fluid (Donald,

54 2010), suggesting that the beneficial result of the regimen was not related to the local effect in

55 CSF.

56 Data of intensified regimens in HIV-related TB other than TB meningitis are lacking. In the

57 present study, we hypothesized that an iATT could also reduce mortality in other forms of TB.

58 We aimed to compare the survival of HIV-infected patients with TB treated with a standard ATT

59 (sATT) and an iATT (with and without STM) during the first two weeks of chemotherapy. 


\section{Methods}

\section{Setting and design}

63 The Vicente Ferrer HIV Cohort Study (VFHCS) is an open cohort study of HIV infected patients

64 who have attended the Rural Development Trust Hospital in Bathalapalli, Anantapur District, 65 AP, India. The hospital provides medical care free of charge to people living with HIV. In our 66 setting, $72 \%$ of the population live in rural areas (Office of The Registrar General \& Census

67 Commissioner, India, 2011). The HIV epidemic is largely driven by heterosexual transmission 68 and it is characterized by low CD4 cell counts at presentation, poor socioeconomic conditions 69 and high levels of illiteracy (Alvarez-Uria et al., 2012a,b, 2013c). The VFHCS is registered at 70 ClinicalTrials.gov (number NCT02454569).

71 For this study, we included all HIV infected patients diagnosed with tuberculosis from 1 June 722012 to 12 May 2015 from the VFHCS database. The selection of patients from the database was 73 executed on 16 November 2015. Patients with tuberculous meningitis were excluded. There were 74 no other exclusion criteria.

75 The selection of variables included in the multivariate analysis was performed based on previous 76 studies investigating risk factors for mortality (Alvarez-Uria et al., 2012a, 2013b, 2014a,b; Kim 77 et al., 2012; Baghaei et al., 2014). Designation of the community of patients was performed by 78 self-identification. Scheduled caste community is marginalised in the traditional Hindu caste 79 hierarchy and, therefore, suffers social and economical exclusion and disadvantage (Gang, Sen \& 80 Yun, 2002). Scheduled tribe community is generally geographically isolated with limited 81 economical and social contact with the rest of the population (Gang, Sen \& Yun, 2002).

82 Scheduled castes and scheduled tribes are considered socially disadvantaged communities and 83 are supported by positive discrimination schemes operated by the Government of India (Alvarez84 Uria, Midde \& Naik, 2012). The estimated glomerular filtration rate (EGFR) was calculated 
85 using the Chronic Kidney Disease Epidemiology Collaboration (CKD-EPI) equation (Teo et al.,

86 2011; Lucas et al., 2014). Mild extrapulmonary TB was defined in patients diagnosed with TB

87 pleuritis or peripheral lymphadenitis (but not other forms of extrapulmonary TB) and no acid-

88 fast bacilli in sputum (Alvarez-Uria et al., 2012a).

\section{Diagnosis of TB}

90 Acid fast bacilli staining of sputum and chest radiograph were performed for all patients with a

91 clinical suspicion of TB. Analysis of cerebrospinal fluid, pleural fluid or ascitic fluid was

92 performed if there were signs of neurological involvement, pleural fluid in the chest radiograph

93 or ascites, respectively. In smear-negative patients complaining of important weight loss, an

94 abdominal ultrasound was performed to search for signs of abdominal TB (Tarantino et al., 2003;

95 Sharma et al., 2007).

96 The diagnosis of TB was made according to World Health Organization recommendations for

97 the definition of TB case and the locally available standard of care (WHO, 2010). Thus, TB

98 diagnosis was based on the presence of acid fast bacilli on sputum smear, caseating or

99 necrotizing granuloma in clinical specimens, or clinical presentation suggestive of TB along with

100 supportive findings in the chest radiograph, abdominal ultrasound or laboratory results from

101 biological fluids.

\section{Treatment during the first two weeks of ATT}

103 Patients were divided into three treatment groups following an intention to treat analysis. Patients

104 in the sATT group received isoniazid $300 \mathrm{mg}$, rifampicin $450 \mathrm{mg}$, ethambutol $800 \mathrm{mg}$, and

105 pyrazinamide $1500 \mathrm{mg}$. Patients in the iATT group received isoniazid $300 \mathrm{mg}$, rifampicin 900

$106 \mathrm{mg}$, pyrazinamide $1500 \mathrm{mg}$ and levofloxacin $1000 \mathrm{mg}$. In patients from the iATT+STM group,

107 STM $750 \mathrm{mg}$ (intramuscular) was added to the iATT regimen. Co-trimoxazole prophylaxis was 
108 given to all patients. All patients were admitted to the hospital and those not on ART at the time

109 of ATT initiation were counselled to start ART between 2 to 8 weeks after hospital discharge.

\section{Statistical analysis}

111 We used time-to-event methods to study the mortality during the first twelve months after

112 starting ATT. Time was measured from ATT initiation to death. Patients who did not die during

113 the study period were censored at twelve months or at their latest visit date, whichever occurred

114 first. Univariate and multivariate analyses were performed using Cox proportional hazard

115 models. The proportional hazard assumption was assessed performing log-log survival curves

116 based on Schoenfeld residuals (Kleinbaum \& Klein, 2005). The log-linearity assumption was

117 checked for all continuous variables, and CD4+ lymphocyte concentration in blood had to be log

118 transformed to achieve log-linearity.

119 Furthermore, we performed an additional analysis using inverse probability of treatment

120 weighting (IPTW) (McCaffrey et al., 2013). To minimize the effect of confounding and obtain

121 an unbiased estimate of the treatment effects, the strongest predictors of mortality were balanced

122 using propensity score methods. The strongest predictors of mortality were selected

123 parsimoniously using a backward elimination method that roughly imitates selection according

124 to a minimal Akaike's information criterion (Royston \& Sauerbrei, 2008). Propensity scores

125 were estimated via boosted models using the "twang" package in the R statistical computing

126 environment (R Foundation for Statistical Computing, Vienna, Austria), which takes into

127 account non-linear effects and interactions (Ridgeway et al., 2013). To select the optimal

128 interation of generalized boosted models, we set to minimize the means of absolute standardized

129 differences (McCaffrey et al., 2013). The propensity scores were used to estimate stabilized

130 weights (McCaffrey et al., 2013). These sampling weights were used to compare the mortality of 
131 the sATT group and the $\mathrm{iATT}+\mathrm{STM}$ group using robust variance to account for the weighted

132 nature of the sample (Austin, 2013). To investigate treatment effect modification, all two-way

133 interactions were assessed using multivariate fractional polynomials (Royston \& Sauerbrei,

$1342009,2014)$.

135 Except for the estimation of propensity scores, statistical analysis was performed using Stata

136 Statistical Software (Stata Corporation. Release 13.1. College Station, Texas, USA).

137 The VFHCS was performed according to the principles of the Declaration of Helsinki, and was

138 approved by the Ethics Committee of the Rural Development Trust Hospital (Reference number

139 OS/003). Written informed consent was given by patients or caretakers for their information to

140 be stored in the study database and used for research. 


\section{Results}

143 During the study period, 1615 patients started ATT; 847 were included in the sATT group, 322

144 in the iATT group, and 446 in the iATT+STM group. Baseline characteristics of patients by

145 treatment group are presented in Table 1. The proportion of patients previously treated of

146 tuberculosis was higher in the iATT+STM group (43\%) than the one in the sATT group (19.2\%)

147 and in the iATT group (none). This is because the Indian Guidelines for tuberculosis recommend

148 adding STM during the first two months of ATT in patients who had received ATT for at least

149 one month in the past (Ministry of Health and Family Welfare India, 2005).

150 Patients in the sATT group had higher concentrations of serum albumin, higher EGFRs and

151 lower blood urea nitrogen (BUN)/creatinine ratios. Other differences were not statistically

152 significant. Weight was measured in 780 patients in the sATT group, 289 patients in the iATT

153 group and 401 patients in the $\mathrm{iATT}+\mathrm{STM}$ group, and the median weight was $47 \mathrm{~kg}$ (interquartile

154 range [IQR], 40-55), $47 \mathrm{~kg}$ (IQR, 40-55), and $45 \mathrm{~kg}$ (IQR, 40-52), respectively. Thus, the

155 median dose of rifampicin was $9.6 \mathrm{mg} / \mathrm{kg}(\mathrm{IQR}, 8.2-11.3)$ in the sATT group, $19.1 \mathrm{mg} / \mathrm{kg}$ (IQR,

$15616.4-22.5)$ in the iATT group and $20 \mathrm{mg} / \mathrm{kg}(\mathrm{IQR}, 17.3-22.5)$ in the iATT+STM group.

157 Univariate and multivariate analysis of factors associated with mortality are presented in Table

158 2. After adjusting for other covariates, there were no mortality differences between the sATT and

159 the iATT groups, but the use of iATT+STM versus sATT was associated with a $28 \%$ mortality

160 risk reduction (adjusted hazard ratio [aHR] 0.72, 95\% confidence interval [CI] 0.57-0.91)

161 compared with sATT. Other factors associated with mortality were low albumin concentrations

162 (aHR 0.47 per increase of $1 \mathrm{~g} / \mathrm{dl}, 95 \%$ CI 0.41 to 0.54 ), low CD4+ lymphocyte concentrations

163 (aHR 0.76 per increase of 1 log-CD4 cells, 95\% CI 0.69 to 0.83 ), high urea concentrations (aHR

1641.008 per increase of $1 \mathrm{mg} / \mathrm{dl}, 95 \%$ CI 1.004 to 1.013 ), high BUN/creatinine ratios (aHR 1.02,

$16595 \%$ CI 1.01 to 1.031 ) and lower EGFR (aHR 0.994 per increase of $1 \mathrm{ml} / \mathrm{min} / 1.73 \mathrm{~m}^{2}, 95 \%$ CI 
1660.99 to 0.999$)$. Having mild extrapulmonary TB was associated with reduced risk of death (aHR

$1670.58,95 \%$ CI 0.43 to 0.78$)$.

168 In a sensitivity analysis, we compared only the sATT group and iATT+STM group using IPTW.

169 Variables statistically associated with mortality in the multivariate analysis were balanced using

170 propensity score methods. At baseline, the sATT group had higher mean of serum albumin

171 concentration, lower mean of EGFR, and lower mean of BUN/Creatinine ratio than the

172 iATT+STM group (Table 3). These differences were considerably reduced after IPTW. The

173 median of propensity scores was 0.3 (IQR $0.25-0.37$ ) in the sATT group and 0.39 (IQR, 0.32-

174 0.51) in the iATT+STM group. The mean standardized difference and the mean Kolmogorov-

175 Smirnov statistic was 0.111 and 0.064 , respectively before IPTW, and 0.040 and 0.029 ,

176 respectively after IPTW. The maximum standardized difference and the maximum Kolmogorov-

177 Smirnov statistic was 0.349 and 0.192 , respectively before IPTW, and 0.0858 and 0.058 ,

178 respectively after IPTW.

179 Stabilized sampling weights were used to estimate Kaplan-Meier survival curves and Cox

180 proportional hazards. In Figure 1, we present the Kaplan-Meier survival estimates. The use of

181 iATT+STM was associated with a significant reduction in mortality (HR 0.766, 95\% CI 0.67-

182 0.96). While analysing interactions between treatment and other predictors of mortality, we

183 found that baseline serum albumin concentrations modified significantly the survival effects seen

184 with the iATT + STM regimen (P-value for interactions=0.0003). Compared with sATT, the

$185 \mathrm{iATT}+\mathrm{STM}$ regimen was more beneficial for patients with higher serum albumin concentrations

186 than for those with more severe hypoalbuminemia (Figure 2).

187

188 


\section{Discussion}

190 HIV-associated TB is difficult to treat. According to the latest Global TB Report (World Health

191 Organization, 2015), nearly one third of HIV-infected patients with TB die with the current

192 standard of care.

193 In a previous study from our cohort, we showed that adding STM to an intensified ATT could

194 reduce mortality in HIV infected patients with TB meningitis (Alvarez-Uria et al., 2015). Given

195 the poor penetration in cerebrospinal fluid of STM (Kaojarern et al., 1991; Ellard, Humphries \&

196 Allen, 1993), these findings were intriguing and suggested that the synergetic effect of STM and

197 the iATT could be also beneficial for other forms to TB. The results of the present study

198 confirmed this hypothesis. The use of the iATT regimen was not able to improve survival

199 compared with the standard of care. However, when STM was added to the iATT, we observed a

200 statistically and clinically significant mortality reduction.

201 In fact, the synergetic effect of STM and other anti-tuberculosis drugs is not new. In patients

202 with pulmonary tuberculosis, the combination of rifampicin and STM has a strong bactericidal

203 activity during the first six days of ATT (Jindani, Doré \& Mitchison, 2003). In the same study,

204 ethambutol, which was not used in our iATT regimen, had an antagonistic effect when combined

205 with other drugs (Jindani, Doré \& Mitchison, 2003). Moreover, in two phase II clinical trials,

206 substitution of ethambutol with fluoroquinolones resulted in a more rapid decline in bacterial

207 load and higher proportion of patients achieved TB culture negativity at eight weeks (Rustomjee

208 et al., 2008; Conde et al., 2009). However, in our study, substitution of ethambutol with

209 levofloxacin did not improve survival in the iATT group. New studies are needed to clarify if the

210 synergetic effect on survival of STM and the iATT could be explained by the higher doses of

211 rifampicin, the absence of ethambutol, the addition of levofloxacin or combinations of these

212 factors. 
213 On the other hand, a more rapid bactericidal activity during the first days of treatment might not

214 be beneficial to all patients. In our study, patients with severe hypoalbuminemia did not benefit

215 from the use of the iATT+STM regimen. These patients were likely to have more advanced

216 forms of TB and a rapid killing of mycobacteria might have led to a higher inflammatory

217 response (Ordonez et al., 2014). Then again, hypoalbuminemia has been associated with lower

218 concentrations of antimycobacterial drugs in patients with pulmonary TB (Tappero et al., 2005).

219 New studies investigating new treatment approaches in this particularly vulnerable group are

220 urgently needed.

221 The study has some limitations. Observational studies can be biased due to unknown

222 confounders not included in the multivariate analysis. Unlike in clinical trials, treatment groups

223 were not uniformly balanced. Patients in the iATT+STM group were more likely to be

224 previously treated of tuberculosis, which is a known factor related to poorer prognosis (Santha et

225 al., 2002; Jones-López et al., 2011; Alvarez-Uria et al., 2012a). However, in the sensitivity

226 analysis using IPTW, being previously treated of tuberculosis was not included in the

227 multivariate analysis and the use of iATT+STM remained statistically associated with improved

228 survival. One of the most common side effect of STM is nephrotoxicity. It could be possible that

229 the use of STM could have resulted in higher probability of acute kidney injury, but we did not

230 collect information of renal function after ATT initiation, so we cannot compare nephrotoxicity

231 among treatment groups. Nevertheless, we performed extensive analysis of baseline renal

232 function with different parameters. Kidney dysfunction was associated with higher risk of death,

233 but there was no interaction between baseline kidney dysfunction and STM use in terms of

234 increased mortality. The study was done in a resource-limited setting, so we did not confirm TB

235 diagnosis by mycobacterial culture. In addition, we did not have information about the drug 
236 resistance of mycobacteria among treatment groups. However, patients in the iATT+STM group

237 were more likely to have been treated of TB in the past, which is a well-known factor for

238 resistant TB. Then again, severely ill patients were not excluded, so the study reflects the "real-

239 life" of HIV-associated TB in a resource-poor setting, so our results could be generalized to

240 similar settings in developing countries with high prevalence of TB and HIV.

\section{Conclusions}

242 The results of this study are consistent with previous studies from our cohort showing improved

243 survival when STM is combined with an iATT regimen with higher doses of rifampicin and

244 substitution of ethambutol with levofloxacin. However, the survival benefits of the new regimen

245 was not evenly distributed among all patients. The new regimen did not reduce mortality in those

246 patients with severe hypoalbuminemia. The study is observational in nature, so we should be

247 cautious about our conclusions. However, given the high mortality of HIV-related TB, the results

248 of this study deserve further research, ideally through a randomized clinical trial. 


\section{References}

251 Alvarez-Uria G., Naik PK., Pakam R., Bachu L., Midde M. 2012a. Natural history and factors

252

253

254

255

256

257

258

259

260

261

262

263

264

265

266

267

268

269

270

271

associated with early and delayed mortality in HIV infected patients treated of tuberculosis under directly observed treatment short course (DOTS) strategy: a prospective cohort study in India. Interdiscip Perspect Infect Dis 2012:502012.

Alvarez-Uria G., Midde M., Pakam R., Naik PK. 2012b. Gender differences, routes of transmission, socio-demographic characteristics and prevalence of HIV related infections of adults and children in an HIV cohort from a rural district of India. Infect Dis Rep 4:e19. DOI: 10.4081/idr.2012.e19.

Alvarez-Uria G., Midde M., Pakam R., Naik PK. 2013a. Initial Antituberculous Regimen with Better Drug Penetration into Cerebrospinal Fluid Reduces Mortality in HIV Infected Patients with Tuberculous Meningitis: Data from an HIV Observational Cohort Study. Tuberculosis research and treatment 2013:242604. DOI: 10.1155/2013/242604.

Alvarez-Uria G., Midde M., Pakam R., Naik PK. 2013b. Diagnostic and Prognostic Value of Serum Albumin for Tuberculosis in HIV Infected Patients Eligible for Antiretroviral Therapy: Datafrom an HIV Cohort Study in India. BioImpacts: BI 3:123-128. DOI: 10.5681/bi.2013.025.

Alvarez-Uria G., Pakam R., Midde M., Naik PK. 2013c. Entry, Retention, and Virological Suppression in an HIV Cohort Study in India: Description of the Cascade of Care and Implications for Reducing HIV-Related Mortality in Low- and Middle-Income Countries. Interdisciplinary Perspectives on Infectious Diseases 2013:384805. DOI: $10.1155 / 2013 / 384805$. 
272 Alvarez-Uria G., Midde M., Pakam R., Naik PK. 2014a. Directly-observed intermittent therapy

273

274

275

276

277

278

279

280

281

282

283

284

285

286

287

288

289

290

291

292

293

versus unsupervised daily regimen during the intensive phase of anti-tuberculosis therapy in HIV infected patients. BioMed research international 2014:937817.

Alvarez-Uria G., Pakam R., Midde M., Naik PK. 2014b. Incidence and mortality of tuberculosis before and after initiation of antiretroviral therapy: an HIV cohort study in India. Journal of the International AIDS Society 17:19251. DOI:

http://dx.doi.org/10.7448/IAS.17.1.19251.

Alvarez-Uria G., Pakam R., Midde M., Yalla PS., Naik PK. 2015. Adding Streptomycin to an Intensified Regimen for Tuberculous Meningitis Improves Survival in HIV-Infected Patients. Interdisciplinary Perspectives on Infectious Diseases 2015:535134. DOI: $10.1155 / 2015 / 535134$.

Alvarez-Uria G., Midde M., Naik PK. 2012. Socio-demographic risk factors associated with HIV infection in patients seeking medical advice in a rural hospital of India. $J$ Public health Res 1:e14. DOI: 10.4081/jphr.2012.e14.

Austin PC. 2013. A tutorial on the use of propensity score methods with survival or time-toevent outcomes: reporting measures of effect similar to those used in randomized experiments. Statistics in medicine. DOI: 10.1002/sim.5984.

Baghaei P., Marjani M., Tabarsi P., Moniri A., Rashidfarrokhi F., Ahmadi F., Nassiri A-A., Masjedi M-R., Velayati AA., Cattamanchi A. 2014. Impact of chronic renal failure on anti-tuberculosis treatment outcomes. The International Journal of Tuberculosis and Lung Disease: The Official Journal of the International Union Against Tuberculosis and Lung Disease 18:352-356. DOI: 10.5588/ijtld.13.0726. 
294 Conde MB., Efron A., Loredo C., De Souza GRM., Graça NP., Cezar MC., Ram M., Chaudhary 295 MA., Bishai WR., Kritski AL., Chaisson RE. 2009. Moxifloxacin versus ethambutol in 296 the initial treatment of tuberculosis: a double-blind, randomised, controlled phase II trial. Lancet 373:1183-1189. DOI: 10.1016/S0140-6736(09)60333-0.

298

299

300

301

302

303

304

305

306

307

308

309

310

311

312

313

314

315

316

Donald PR. 2010. Cerebrospinal fluid concentrations of antituberculosis agents in adults and children. Tuberculosis (Edinburgh, Scotland) 90:279-292. DOI: 10.1016/j.tube.2010.07.002.

Ellard GA., Humphries MJ., Allen BW. 1993. Cerebrospinal fluid drug concentrations and the treatment of tuberculous meningitis. The American Review of Respiratory Disease 148:650-655. DOI: 10.1164/ajrccm/148.3.650.

Gang IN., Sen K., Yun MS. 2002. Caste, Ethnicity, and Poverty in Rural India. IZA.

Jindani A., Doré CJ., Mitchison DA. 2003. Bactericidal and sterilizing activities of antituberculosis drugs during the first 14 days. American Journal of Respiratory and Critical Care Medicine 167:1348-1354. DOI: 10.1164/rccm.200210-1125OC.

Jones-López EC., Ayakaka I., Levin J., Reilly N., Mumbowa F., Dryden-Peterson S., Nyakoojo G., Fennelly K., Temple B., Nakubulwa S., Joloba ML., Okwera A., Eisenach KD., McNerney R., Elliott AM., Ellner JJ., Smith PG., Mugerwa RD. 2011. Effectiveness of the Standard WHO Recommended Retreatment Regimen (Category II) for Tuberculosis in Kampala, Uganda: A Prospective Cohort Study. PLoS Med 8:e1000427. DOI: 10.1371/journal.pmed.1000427.

Kaojarern S., Supmonchai K., Phuapradit P., Mokkhavesa C., Krittiyanunt S. 1991. Effect of steroids on cerebrospinal fluid penetration of antituberculous drugs in tuberculous meningitis. Clinical Pharmacology and Therapeutics 49:6-12. 
317 Kim CW., Kim S-H., Lee SN., Lee SJ., Lee MK., Lee J-H., Shin KC., Yong SJ., Lee WY. 2012.

318 Risk factors related with mortality in patient with pulmonary tuberculosis. Tuberculosis and Respiratory Diseases 73:38-47. DOI: 10.4046/trd.2012.73.1.38.

320 Kleinbaum DG., Klein M. 2005. Survival Analysis, a Self-Learning Text. Springer.

321 Lucas GM., Ross MJ., Stock PG., Shlipak MG., Wyatt CM., Gupta SK., Atta MG., WoolsKaloustian KK., Pham PA., Bruggeman LA., Lennox JL., Ray PE., Kalayjian RC., HIV Medicine Association of the Infectious Diseases Society of America 2014. Clinical practice guideline for the management of chronic kidney disease in patients infected with HIV: 2014 update by the HIV Medicine Association of the Infectious Diseases Society of America. Clinical Infectious Diseases: An Official Publication of the Infectious Diseases Society of America 59:e96-138. DOI: 10.1093/cid/ciu617.

McCaffrey DF., Griffin BA., Almirall D., Slaughter ME., Ramchand R., Burgette LF. 2013. A tutorial on propensity score estimation for multiple treatments using generalized boosted models. Statistics in medicine 32:3388-3414. DOI: 10.1002/sim.5753.

Ministry of Health and Family Welfare India. 2005. Technical and operational guideline for tuberculosis control.

333 Office of The Registrar General \& Census Commissioner, India 2011. Census of India.

334 Ordonez AA., Pokkali S., DeMarco VP., Klunk M., Mease RC., Foss CA., Pomper MG., Jain 335 SK. 2014. Radioiodinated DPA-713 Imaging Correlates with Bactericidal Activity of Tuberculosis Treatments in Mice. Antimicrobial Agents and Chemotherapy 59:642-649. DOI: 10.1128/AAC.04180-14. 
338 Ridgeway G., McCaffrey D., Morral A., Burgette L., Griffin BA. 2013. Toolkit for Weighting

339 and Analysis of Nonequivalent Groups: A tutorial for the twang package. $R$ vignette.

$340 \quad R A N D$.

341 Royston P., Sauerbrei W. 2008. Multivariable Model - Building: A Pragmatic Approach to 342 Regression Anaylsis based on Fractional Polynomials for Modelling Continuous

$343 \quad$ Variables. John Wiley \& Sons.

344 Royston P., Sauerbrei W. 2009. Two techniques for investigating interactions between treatment 345 and continuous covariates in clinical trials. Stata Journal 9:230.

346 Royston P., Sauerbrei W. 2014. Interaction of treatment with a continuous variable: simulation 347 study of power for several methods of analysis. Statistics in Medicine 33:4695-4708.

348 DOI: $10.1002 / \operatorname{sim} .6308$.

349 Ruslami R., Ganiem AR., Dian S., Apriani L., Achmad TH., van der Ven AJ., Borm G., 350 Aarnoutse RE., van Crevel R. 2013. Intensified regimen containing rifampicin and 351 moxifloxacin for tuberculous meningitis: an open-label, randomised controlled phase 2 352 trial. The Lancet infectious diseases 13:27-35. DOI: 10.1016/S1473-3099(12)70264-5.

353 Rustomjee R., Lienhardt C., Kanyok T., Davies GR., Levin J., Mthiyane T., Reddy C., Sturm 354 AW., Sirgel FA., Allen J., Coleman DJ., Fourie B., Mitchison DA., Gatifloxacin for TB (OFLOTUB) study team 2008. A Phase II study of the sterilising activities of ofloxacin, gatifloxacin and moxifloxacin in pulmonary tuberculosis. The International Journal of Tuberculosis and Lung Disease: The Official Journal of the International Union Against Tuberculosis and Lung Disease 12:128-138.

Santha T., Garg R., Frieden TR., Chandrasekaran V., Subramani R., Gopi PG., Selvakumar N., Ganapathy S., Charles N., Rajamma J., Narayanan PR. 2002. Risk factors associated with 
361

362

363

364

365

366

367

368

369

370

371

372

373

374

375

376

377

378

379

380

381

382

383

default, failure and death among tuberculosis patients treated in a DOTS programme in Tiruvallur District, South India, 2000. The international journal of tuberculosis and lung disease: the official journal of the International Union against Tuberculosis and Lung Disease 6:780-788.

Sharma SK., Smith-Rohrberg D., Tahir M., Mohan A., Seith A. 2007. Radiological manifestations of splenic tuberculosis: a 23-patient case series from India. The Indian journal of medical research 125:669-678.

Tappero JW., Bradford WZ., Agerton TB., Hopewell P., Reingold AL., Lockman S., Oyewo A., Talbot EA., Kenyon TA., Moeti TL., Moffat HJ., Peloquin CA. 2005. Serum concentrations of antimycobacterial drugs in patients with pulmonary tuberculosis in Botswana. Clinical Infectious Diseases: An Official Publication of the Infectious Diseases Society of America 41:461-469. DOI: 10.1086/431984.

Tarantino L., Giorgio A., de Stefano G., Farella N., Perrotta A., Esposito F. 2003. Disseminated mycobacterial infection in AIDS patients: abdominal US features and value of fineneedle aspiration biopsy of lymph nodes and spleen. Abdominal imaging 28:602-608.

Te Brake L., Dian S., Ganiem AR., Ruesen C., Burger D., Donders R., Ruslami R., van Crevel R., Aarnoutse R. 2015. Pharmacokinetic/pharmacodynamic analysis of an intensified regimen containing rifampicin and moxifloxacin for tuberculous meningitis. International Journal of Antimicrobial Agents. DOI: 10.1016/j.ijantimicag.2014.12.027.

Teo BW., Xu H., Wang D., Li J., Sinha AK., Shuter B., Sethi S., Lee EJC. 2011. GFR estimating equations in a multiethnic Asian population. American Journal of Kidney Diseases: The Official Journal of the National Kidney Foundation 58:56-63. DOI:

10.1053/j.ajkd.2011.02.393. 
384 WHO 2010. Treatment of Tuberculosis: guidelines for national programmes. 4th Ed.

385 World Health Organization. 2015. Global tuberculosis report 2015.

386 
387 Tables

388 Table 1. Baseline characteristics by treatment group.

\begin{tabular}{|c|c|c|c|c|}
\hline & $\begin{array}{l}\text { Standard ATT } \\
\quad(\mathbf{n}=\mathbf{8 4 7})\end{array}$ & $\begin{array}{c}\text { Intensified ATT } \\
(\mathbf{n}=322)\end{array}$ & $\begin{array}{c}\text { Intensified } \\
\text { ATT+STM } \\
(n=446)\end{array}$ & p-value \\
\hline Gender & & & & 0.183 \\
\hline Male & $557(65.76)$ & $203(63.04)$ & $309(69.28)$ & \\
\hline Female & $290(34.24)$ & $119(36.96)$ & $137(30.72)$ & \\
\hline On ART & & & & 0.429 \\
\hline No & $576(68)$ & $231(71.74)$ & $303(67.94)$ & \\
\hline Yes & $271(32)$ & $91(28.26)$ & $143(32.06)$ & \\
\hline $\begin{array}{l}\text { Disadvantaged } \\
\text { community }\end{array}$ & & & & 0.796 \\
\hline No & $579(68.36)$ & $220(68.32)$ & $297(66.59)$ & \\
\hline Yes & $268(31.64)$ & $102(31.68)$ & $149(33.41)$ & \\
\hline Homeless & & & & 0.786 \\
\hline No & $831(98.11)$ & $317(98.45)$ & $436(97.76)$ & \\
\hline Yes & $16(1.89)$ & $5(1.55)$ & $10(2.24)$ & \\
\hline Previous ATT & & & & $<0.001$ \\
\hline No & $684(80.76)$ & $322(100)$ & $254(56.95)$ & \\
\hline Yes & $163(19.24)$ & $0(0)$ & $192(43.05)$ & \\
\hline $\begin{array}{l}\text { Mild extrapulmonary } \\
\text { TB }\end{array}$ & & & & 0.29 \\
\hline No & $688(81.23)$ & $252(78.26)$ & $369(82.74)$ & \\
\hline Yes & $159(18.77)$ & $70(21.74)$ & $77(17.26)$ & \\
\hline $\begin{array}{l}\text { Age (years), median } \\
\text { (IQR) }\end{array}$ & $36.07(30.02-44.42)$ & $\begin{array}{c}34.995(29.98- \\
44.97)\end{array}$ & $\begin{array}{l}36.28(31.19- \\
43.97)\end{array}$ & 0.43 \\
\hline $\begin{array}{l}\text { Albumin (g/dl), median } \\
\text { (IQR) }\end{array}$ & $3.2(2.7-3.7)$ & $3.15(2.7-3.6)$ & $3.1(2.6-3.5)$ & 0.0013 \\
\hline $\begin{array}{l}\text { CD4 count (cells/ } \mu \mathrm{l}), \\
\text { median (IQR) }\end{array}$ & $116(59-222)$ & $102(49-210)$ & $118(56-242)$ & 0.16 \\
\hline $\begin{array}{l}\text { Urea (mg/dl), median } \\
\text { (IQR) }\end{array}$ & $23.5(17.3-34.9)$ & $23.6(16.5-35.1)$ & $23.3(17-35.7)$ & 0.9 \\
\hline $\begin{array}{l}\text { BUN/Creatinine ratio, } \\
\text { median (IQR) }\end{array}$ & $14.23(10.67-19.19)$ & $16.71(12.76-22.4)$ & $\begin{array}{l}16.92(12.4- \\
22.59)\end{array}$ & $<0.001$ \\
\hline $\begin{array}{l}\text { EGFR }\left(\mathrm{mL} / \mathrm{min} / 1.73 \mathrm{~m}^{2}\right) \text {, } \\
\text { median (IQR) }\end{array}$ & $109(86-122)$ & $118(98-133)$ & $118.5(100-134)$ & $<0.001$ \\
\hline
\end{tabular}

389

390

391

392

393

394

ART, antiretroviral therapy; ATT, anti-tuberculosis therapy; BUN, blood urea nitrogen; EGFR, estimated filtration rate; IQR, interquartile range; STM, streptomycin.

Data are presented as No. (\%) unless otherwise indicated. P-values were calculated using $\mathrm{Chi}^{2}$ test for categorical variables and Kruskal-Wallis rank test for continuous variables. 
395 Table 2. Univariate and multivariate analyses of risk factors for mortality using Cox 396 proportional hazard models.

\begin{tabular}{|c|c|c|}
\hline & HR $(95 \%$ CI $)$ & Adjusted HR (95\% CI) \\
\hline Female & $1.030(0.857-1.238)$ & $1.046(0.856-1.277)$ \\
\hline On ART & $1.038(0.860-1.252)$ & $1.333 *(1.088-1.633)$ \\
\hline Disadvantaged community & $0.917(0.759-1.108)$ & $0.871(0.718-1.057)$ \\
\hline Homeless & $1.750 *(1.064-2.880)$ & $1.480(0.895-2.449)$ \\
\hline Previous ATT & $1.120(0.912-1.376)$ & $1.163(0.917-1.474)$ \\
\hline Mild extrapulmonary TB & $0.418 *(0.312-0.560)$ & $0.581 *(0.432-0.781)$ \\
\hline Age (years) & $1.010 *(1.002-1.019)$ & $0.998(0.988-1.009)$ \\
\hline $\operatorname{Albumin}(\mathrm{g} / \mathrm{dl})$ & $0.406 *(0.356-0.461)$ & $0.471 *(0.411-0.540)$ \\
\hline Log-CD4 count (cells/ $\mu \mathrm{l})$ & $0.652 *(0.602-0.705)$ & $0.759 *(0.694-0.830)$ \\
\hline Urea (mg/dl) & $1.017 *(1.015-1.019)$ & $1.008 *(1.004-1.013)$ \\
\hline BUN/Creatinine ratio & $1.043 *(1.035-1.050)$ & $1.020 *(1.010-1.031)$ \\
\hline $\operatorname{EGFR}\left(\mathrm{mL} / \mathrm{min} / 1.73 \mathrm{~m}^{2}\right)$ & $0.990 *(0.987-0.993)$ & $0.994 *(0.990-0.999)$ \\
\hline \multicolumn{3}{|l|}{ ATT } \\
\hline Standard & 1 (Reference) & 1 (Reference) \\
\hline Intensified & $0.952(0.758-1.195)$ & $0.868(0.682-1.103)$ \\
\hline Intensified+STM & $0.837(0.674-1.040)$ & $0.718 *(0.569-0.907)$ \\
\hline
\end{tabular}

397

398

399

400
*P-value $<0.05$; ART, antiretroviral therapy; ATT, anti-tuberculosis therapy; BUN, blood urea nitrogen; EGFR, estimated filtration rate; HR, hazard ratio; STM, streptomycin. 
Table 3. Balance before and after inverse probability of treatment weighting

\begin{tabular}{|c|c|c|c|c|c|c|c|c|}
\hline \multicolumn{9}{|c|}{ BEFORE INVERSE PROBABILITY OF TREATMENT WEIGHTING } \\
\hline & $\begin{array}{c}\text { Mean } \\
\text { (sATT) }\end{array}$ & $\begin{array}{c}\text { Standard } \\
\text { deviation (sATT) }\end{array}$ & $\begin{array}{c}\text { Mean } \\
\text { (iATT+STM) }\end{array}$ & $\begin{array}{c}\text { Standard } \\
\text { deviation } \\
\text { (iATT+STM) }\end{array}$ & $\begin{array}{l}\text { Standardize } \\
\text { d difference }\end{array}$ & P-value & $\begin{array}{c}\mathrm{KS} \\
\text { statistic }\end{array}$ & $\begin{array}{l}\text { KS P- } \\
\text { value }\end{array}$ \\
\hline $\begin{array}{l}\text { Log-CD4 count } \\
\text { (cells/ } \mu \mathrm{l})\end{array}$ & 4.693 & 1.001 & 4.691 & 1.063 & -0.002 & 0.969 & 0.042 & 0.653 \\
\hline Albumin (g/dl) & 3.214 & 0.743 & 3.051 & 0.652 & -0.227 & 0 & 0.106 & 0.002 \\
\hline On ART & 0.32 & 0.466 & 0.321 & 0.467 & 0.001 & 0.98 & 0.001 & 0.98 \\
\hline $\begin{array}{l}\text { Mild } \\
\text { extrapulmonary } \\
\text { TB }\end{array}$ & 0.188 & 0.39 & 0.173 & 0.378 & -0.04 & 0.505 & 0.015 & 0.505 \\
\hline $\begin{array}{l}\text { EGFR } \\
(\mathrm{mL} / \mathrm{min} / 1.73 \\
\left.\mathrm{m}^{2}\right) \\
\end{array}$ & 103.609 & 29.709 & 114.334 & 31.354 & 0.349 & 0 & 0.192 & 0 \\
\hline $\begin{array}{l}\text { BUN/Creatinine } \\
\text { ratio }\end{array}$ & 15.962 & 8.015 & 18.873 & 9.521 & 0.336 & 0 & 0.176 & 0 \\
\hline Urea (mg/dl) & 29.958 & 22.03 & 30.034 & 22.924 & 0.003 & 0.954 & 0.03 & 0.945 \\
\hline \multicolumn{9}{|c|}{ AFTER INVERSE PROBABILITY OF TREATMENT WEIGHTING } \\
\hline & $\begin{array}{c}\text { Mean } \\
\text { (sATT) }\end{array}$ & $\begin{array}{c}\text { Standard } \\
\text { deviation (sATT) }\end{array}$ & $\begin{array}{c}\text { Mean } \\
(\text { iATT+STM) }\end{array}$ & $\begin{array}{c}\text { Standard } \\
\text { deviation } \\
(\mathrm{iATT}+\mathrm{STM})\end{array}$ & $\begin{array}{l}\text { Standardize } \\
\text { d difference }\end{array}$ & P-value & $\begin{array}{c}\mathrm{KS} \\
\text { statistic }\end{array}$ & $\begin{array}{l}\text { KS P- } \\
\text { value }\end{array}$ \\
\hline $\begin{array}{l}\text { Log-CD4 count } \\
(\text { cells } / \mu l)\end{array}$ & 4.693 & 1.009 & 4.66 & 1.06 & -0.032 & 0.608 & 0.03 & 0.955 \\
\hline Albumin (g/dl) & 3.158 & 0.724 & 3.099 & 0.657 & -0.086 & 0.149 & 0.058 & 0.298 \\
\hline On ART & 0.32 & 0.466 & 0.315 & 0.465 & -0.01 & 0.871 & 0.005 & 0.871 \\
\hline $\begin{array}{l}\text { Mild } \\
\text { extrapulmonary } \\
\text { TB }\end{array}$ & 0.185 & 0.388 & 0.173 & 0.378 & -0.032 & 0.597 & 0.012 & 0.597 \\
\hline $\begin{array}{l}\text { EGFR } \\
(\mathrm{mL} / \mathrm{min} / \mathbf{1 . 7 3}\end{array}$ & 106.719 & 30.375 & 108.737 & 30.808 & 0.066 & 0.275 & 0.056 & 0.345 \\
\hline
\end{tabular}




\begin{tabular}{|c|c|c|c|c|c|c|c|c|}
\hline $\left.\mathbf{m}^{2}\right)$ & & & & & & & & \\
\hline $\begin{array}{l}\text { BUN/Creatinine } \\
\text { ratio }\end{array}$ & 16.658 & 8.394 & 17.34 & 8.429 & 0.081 & 0.161 & 0.054 & 0.39 \\
\hline Urea (mg/dl) & 29.89 & 21.778 & 30.228 & 23.54 & 0.015 & 0.809 & 0.028 & 0.978 \\
\hline
\end{tabular}

ART, antiretroviral therapy; iATT, intensified anti-tuberculosis therapy; sATT, standard anti-tuberculosis therapy; BUN, blood urea

nitrogen; EGFR, estimated filtration rate; KS, Kolmogorov-Smirnov; STM, streptomycin. 
Figure 1. Survival curves after inverse probability of treatment weighting

\section{Kaplan-Meier survival estimates}

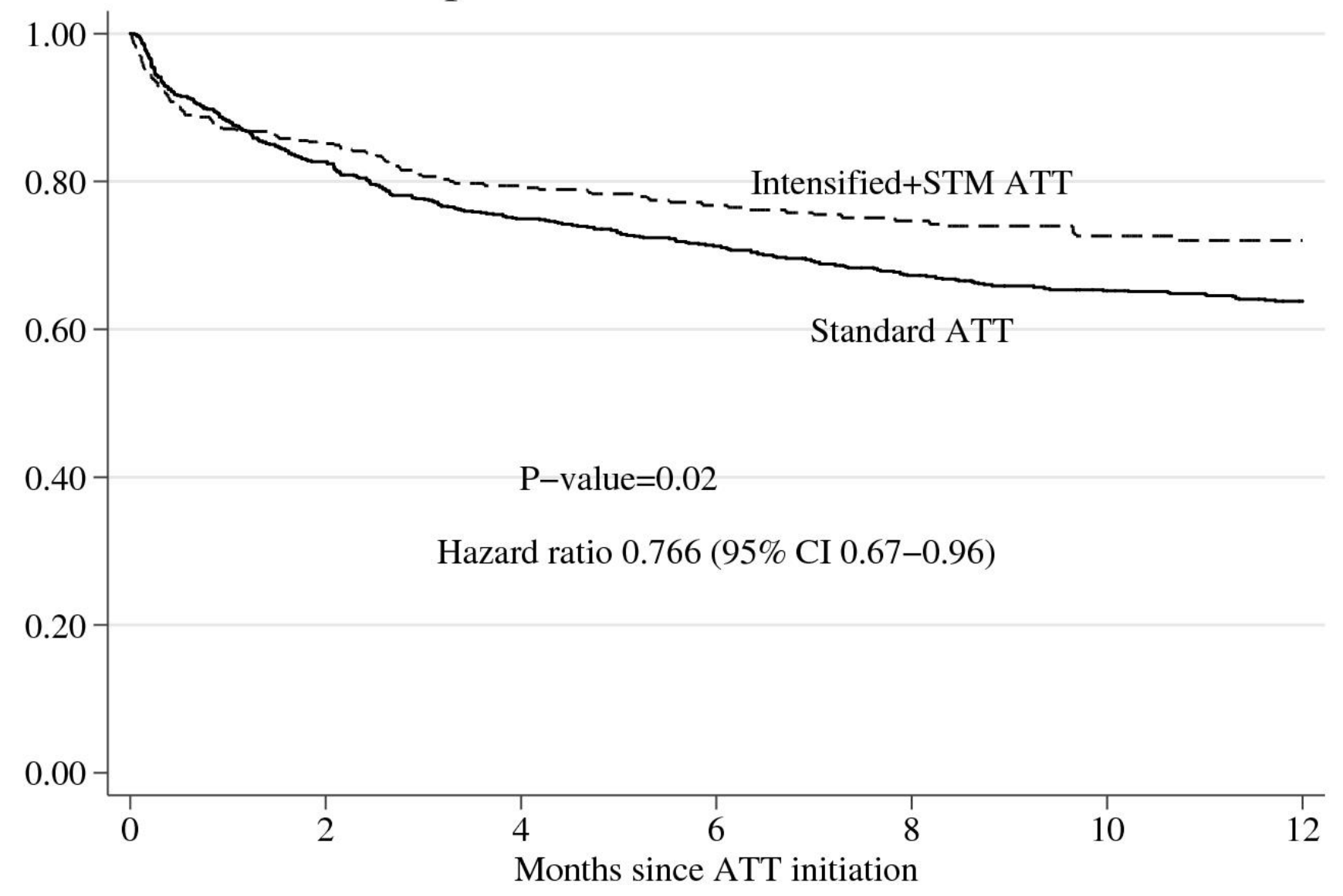

406

ATT, anti-tuberculosis therapy; STM, streptomycin. 


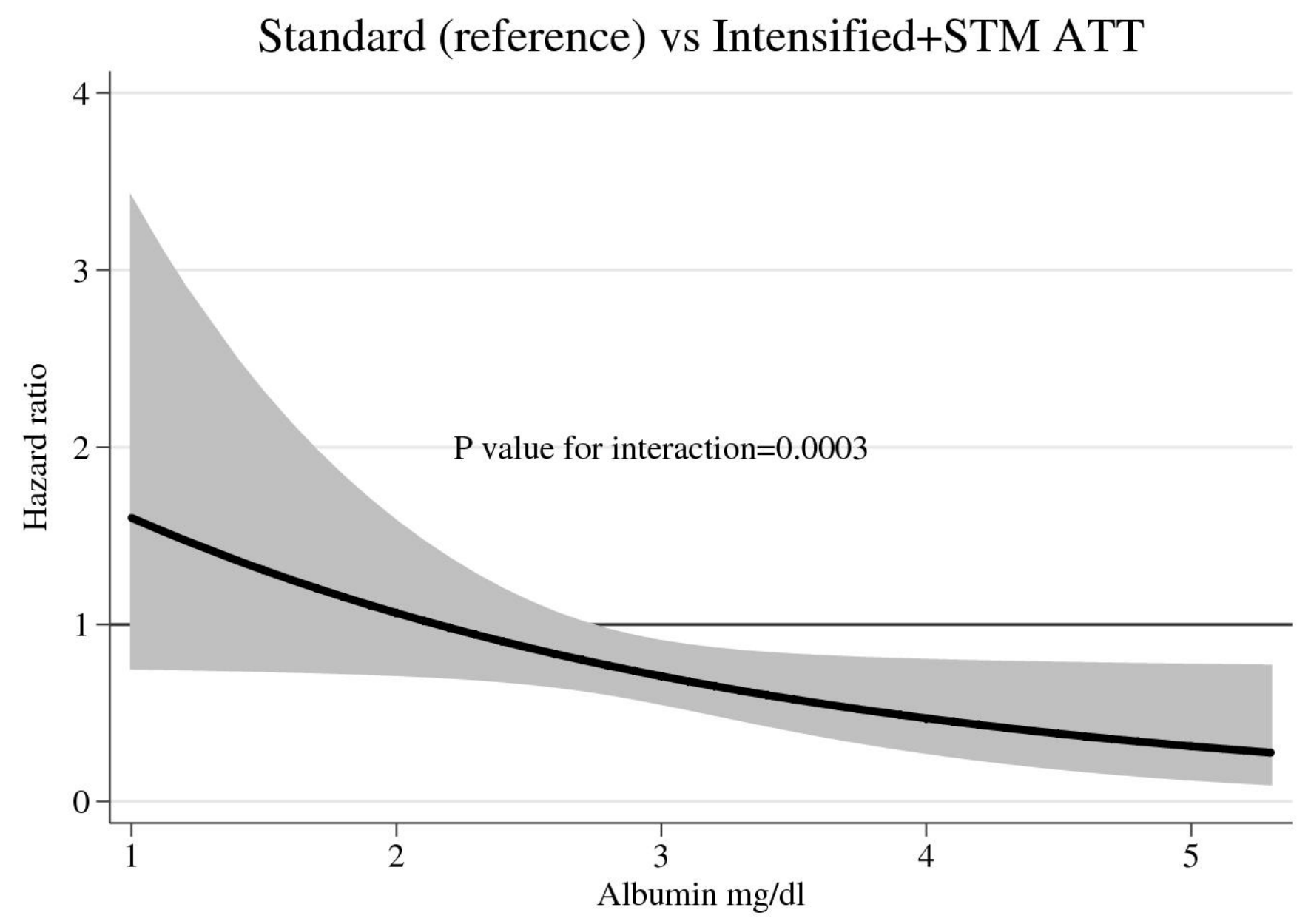

411 ATT, anti-tuberculosis therapy; STM, streptomycin. 